APJML

26,3

408

Received 29 September 2013

Revised 17 November 2013

16 December 2013

Accepted 28 December 2013

\section{Consumer susceptibility to credit card misuse and indebtedness}

\author{
Sandra Awanis and Charles Chi Cui \\ Manchester Business School, University of Manchester, Manchester, UK
}

\section{Abstract}

Purpose - Prior research suggests that payment mechanisms are imbued with cues that affect purchase evaluation and future spending behavior. Credit cards are distinguished from other payment mechanisms as they elicit greater willingness to spend, prompt weaker recollections of past credit expenses and overvaluation of available funds - a phenomena the authors call as "credit card effect." Little is known about the individuals' differential exposure to the credit card effect. The purpose of this paper is to present a new concept and measure of susceptibility to the credit card misuse and indebtedness (SCCMI).

Design/methodology/approach - The study focussed on young credit card users (aged 18-25) from Malaysia, Singapore, and the UK as they represent varying levels of credit card issuance and consumer protection regulations. The authors conducted confirmatory factor analysis and invariance tests to assess the validity, reliability and parsimony of the proposed scale in the three countries. Further, the authors examined the prediction power of SCCMI on consumer tendency to become a revolving credit card debtor.

Findings - Results show that the SCCMI scale is valid, reliable and parsimonious across the multi-country context. The paper provided additional validity support through known-group comparison among various payers of credit card bills.

Research limitations/implications - The convenience sampling used for the study is the main limitation. The findings bear important implications for more socially responsible marketing practice and better public policies in credit carder regulation for protecting young credit card users.

Practical implications - The new concept and measurement scale can be used for identifying the vulnerable individuals in credit card use, assisting consumer knowledge training, improving policies for credit card regulation, and helping credit card providers in socially responsible marketing practice. Social implications - The cross-country validity of the SCCMI scale provides a unique contribution for monitoring and auditing consumer vulnerability in credit card misuse in Asian and European market conditions.

Originality/value - SCCMI offers an original concept that is distinct from previous research in that SCCMI focusses solely on the state of likelihood to commit credit card abuse rather than the behavioral manifestations of credit card misuse. SCCMI provides a new tool for marketers and public policy makers for ethically responsible credit card marketing and regulation to protect youths' benefits.

Keywords Debt, Measurement scale, Consumer vulnerability, Credit card, Susceptibility

Paper type Research paper

\section{Introduction}

In today's vogue toward a cashless society, using credit cards as "plastic" money is now for most people the dominant payment form to replace cash money (Feinberg, 1986; Soman, 2003). Credit cards are regarded as a spending stimulus that allows greater ease of spending than cash. Hence, they elicit certain unique purchasing attitudes (Feinberg, 1986; Prelec and Simester, 2001; Soman, 2001) and are more likely to set some individuals on a path toward indebtedness and personal bankruptcy (Pirog and Roberts, 2007; Szmigin and O'Loughlin, 2010). Research in credit card psychology and behavior has shown how some consumers display greater willingness to spend and make greater value purchases on their credit cards (a phenomenon called "credit card premium"), have weaker recollections of past credit expenses, and overvalue their
Asia Pacific Journal of Marketing and Logistics

Vol. 26 No. 3, 2014

pp. $408-429$

(C) Emerald Group Publishing Limited 1355-5855

DOI 10.1108/APJML-09-2013-0110 
available funds when using credit cards than cash in an otherwise identical purchase situation (Chatterjee and Rose, 2012; Feinberg, 1986) - the phenomena we call as the "credit card effect." It is beyond doubt that early monitoring and gauging consumers' extent of the psychological inclination to the credit card effect is crucial for preventing them from suffering the consequences. Extant literature reveals lack of research in conceptualizing and measuring credit card users' exposure to the credit card effect. To bridge this gap, we present a new psychological concept of susceptibility to credit card misuse and indebtedness (SCCMI) and its measurement scale, which provides a sound means for measuring this vulnerable psychological inclination and facilitating prevention of negative credit card usage.

\section{Effects of payment mechanism on consumer transaction behavior}

Prior investigations concerning the psychological effects of payment mechanisms suggest that the use of a particular payment type influences their present and future spending behavior (Hirschman, 1979; Soman, 2001; Tokunaga, 1993). Indeed, payment mechanisms are imbued with cues that affect purchase evaluation. For example, lack of transparency in a payment format contribute to greater willingness to pay (Soman, 2003), while the presence of temporal separation between payment and consumption affect future purchase behavior (Gourville and Soman, 1998; Soman, 2001). While there is substantial evidence to support the negative impacts of credit card cues on purchase evaluation, little has been done to transform such knowledge into an informative tool for people to assess their likelihood to submit to the psychological effects of payment mechanism.

In comparison to other payment mechanisms, credit card has received greater negative attention from the media (BBC, 2011; Mannings, 1999; SallieMae, 2009), academic studies (Norvilitis et al., 2006; Palmer et al., 2001; Warwick and Mansfield, 2000; Xiao et al., 2011) and public policy alike (Austin and Phillips, 2001; Braunsberger et al., 2004; Henry et al., 2013). This is due to the credit cards' physical characteristics and subsequent psychological effects, particularly when used by inexperienced or vulnerable users (Braunsberger et al., 2004; Norvilitis et al., 2006; Soman and Cheema, 2002; Wang et al., 2011). To curb credit card effects on spending, government intervention imposed stricter rules on credit card targeted marketing to deter over-indebtedness. For example, the 2009 US CARD Act restricted the use of credit card among those aged 21 years or below (unless they show evidence of regular income) and the marketing of credit cards toward college students. Similarly, Malaysia's Bank Negara increased the minimum income required for credit card eligibility from RM 18,000 to RM 24,000 in 2011. Meanwhile, Bruneian and Indonesian government limited minimum age of credit card ownership only to those above 21 years old in 2010 and 2012, respectively.

However, an effective policy or social marketing efforts designed to protect consumer must not result in the marginalization of their vulnerability (Pechmann et al., 2011). For instance, policies that restrict minimum age of credit card ownership may impact even those who are not vulnerable to credit card indebtedness and consequently deter their rights to financial freedom (Braunsberger et al., 2004; Wood, 2010). Furthermore, stringent policies negatively influence the credit card industry's profitability and constrain marketers with inferior marketing strategy. Multiple investigations into the youths' credit card reform suggest that policy changes should be accompanied by behavioral interventions to inform consumers, help reduce risky credit behavior, and help them make optimal credit card usage decisions (Burton, 2008; Soman et al., 2011; Xiao et al., 2011). 
APJML 26,3

410
This study corresponds to these theoretical gaps by presenting a psychometric tool that specifies the psychological attributes of those who are most susceptible to be influenced by the spending cues inherent in credit card purchases. Identifying the consumers' internal characteristics that contribute to their vulnerability aids to advance current knowledge of vulnerable consumers' credit card usage (Baker et al., 2005). In turn, such understanding facilitates a better marketing and policy intervention program that restore control back to the consumers, without forgoing their financial welfare.

\section{Credit card effect}

Extant literature shows that the psychological effects of credit card usage manifest in: first, a greater spending level when using credit cards than other payment mechanisms (known as credit card premium) (Feinberg, 1986; Prelec and Loewenstein, 1998; Prelec and Simester, 2001); second, the difficulty to recall past credit card expenses (Soman, 2001); third, the tendency to overestimate available income when deliberating a credit card purchase (Soman, 2001; Soman and Cheema, 2002), or all these jointly (Soman et al., 2011).

Credit card premium occurs when the use of a credit card heightens an individual's propensity to spend more in comparison with other payment mechanisms in otherwise identical purchase situations (Chatterjee and Rose, 2012; Feinberg, 1986; Hirschman, 1979; Soman, 2001). Prelec and Simester (2001) reported that respondents who pay with credit cards bid a significantly greater amount for tickets to a sporting event, compared to other respondents instructed to pay by cash. Credit card premium is attributed to payment decoupling, which arises when the decision to spend by credit card is temporally separated from the actual parting with money (Prelec and Loewenstein, 1998; Raghubir and Srivastava, 2008). In contrast, cash payments are tightly coupled with the immediate parting of money. Hence, they evoke "pain of paying" (arising from the thoughts about financial sacrifice) which stimulates self-control that subsequently deters spending (Prelec and Loewenstein, 1998). However, this "pain" is absent or reduced during credit card transaction because the outflow of money is deferred to a later date (Chatterjee and Rose, 2012). Hence, payments by credit card become less psychologically punishing and their capacity to deter spending becomes considerably weaker (Loewenstein and O'Donoghue, 2006; Rick et al., 2008).

Credit card effect also exhibits in trivialization of past credit card payments. For instance, writing down a total amount of payment in words and figures on checks left a vivid memory trace of the total payments and stronger association with the act of paying, causing strong memorability (Soman, 2001). In contrast, credit card payments only require signatures or PIN codes. Therefore, the participants who charged expenses into their credit cards tended to show low memorability of past card payments and were more likely to purchase discretionary (unplanned) goods. Hence, consumers may experience trivialization of past credit card payments because they are deficient in accounting for past credit card expenses and incorporating them in future spending decisions (Soman, 2001).

Overvaluation of available income signifies another character of the credit card effect. Consumers who charge their expenses into their credit cards tend to incorrectly estimate their available income, which further undermines their purchase evaluations. Indeed, consumers who undervalue past expenses tend to overvalue their available funds (Soman, 2001). However, a misjudgment of available income is also compounded by the fact that credit cards and credit card limits also foster the illusion that they are 
equitable with having greater purchasing power. For instance, Soman and Cheema (2002) exhibited that young consumers and those with less experience with credit card use treated their credit limit as a signal of their future income. Hence, they tend to infer a larger future income and spend a greater amount than the credit limit allows.

\section{SCCMI}

The previous discussion of the typical manifestations of the credit card effect lends strong support to the view that consumers are often unable to objectively valuate money in light of different payment systems. Yet little is known about how some consumers become more susceptible to credit card temptations than others and how credit card bearers can strive to address their potential susceptibility to credit card effect. In addition, information on how to identify individuals who are susceptible to credit card effect is lacking. Soman (2001) showed that only 35 percent of students who had just paid by credit card could recall the exact amount they had spent, in comparison to 66 percent who paid by cash. This suggests that some of the youth population is more likely than others to experience credit card effect. Overall, this warrants further investigations of consumers who are susceptible to credit card effect and what might need to be done to help them.

This study conceptualizes SCCMI as an individual's propensity to yield to the behavioral outcomes pertaining to the credit card effect by deviating from the rational credit card usage. Decisions that deviate from rational norms are those attributed to impaired cognitive function, such as short-term memory, pattern recognition or lack of self-regulation, rather than those guided by self-reflective determinants of that person's intentions (Kuhl, 1992). Thus, for example, a person is not SCCMI when he/she intends to over-borrow on credit cards to take advantage of the financial system which frees debtors from most personal liabilities following their bankruptcy claims (Wiener et al., 2007).

Individuals are likely to vary in their SCCMI because of the various levels of receptivity toward credit card effect, self-regulation and degree of financial sophistication. A rational and strategic use of credit cards requires a consumer's full awareness of available income and conscious planning to make credit card repayment (including how much to repay and when to make repayments) in order to achieve maximum utility and minimum financial charges. However, consumers tend to make computational or planning errors during credit card usage, which leads to overspending or accumulating interest on credit card balance. This occurs because consumers are receptive toward credit card temptations or persuasions, which are marketed as "benefits" to the consumers, but in actuality might incur further charges or serve to entice consumers to make greater credit card charges/smaller repayments. To illustrate how consumers become receptive to credit card cues, Stewart (2009) and Navarro-Martinez et al. (2011) showed that the presence of a minimum payment option at the end of credit card statements led people to "anchor" their decision frame to this minimum amount. As a result, they tended to make smaller repayments toward their credit card balance. Therefore, it is conceivable that such credit card enticements can influence consumers' decisions in a way that favors greater spending while minimizing savings. Consumers who fully internalize these credit card enticements are susceptible to assimilate behaviors associated with credit card effect.

The degree of self-regulatory capacity is also a likely determinant to an individual's SCCMI. Individuals might be aware of the negative consequences that arise from credit card misuse and indebtedness. However, they may still end up accumulating 
APJML

26,3

412

credit card charges because of low self-regulatory capabilities. Low self-regulation consumers experience dissociation between intentions and their original goals, which expose them to competing with contextually derived action tendencies that interfere with their original intentions (Babin and Darden, 1995; Kuhl, 1981, 1992). Conversely, high self-regulatory consumers are action oriented, i.e. they have firmer intentions and display readiness to act, making them less susceptible to interferences during a process of action (Babin and Darden, 1995). Credit card users with high regulatory capabilities might be aware of the potential negative consequences of indebtedness. Hence, they are able to regulate their credit card usage in such a way as to avoid being charged interest or accumulate unpaid balances. Consumers with low self-regulatory capabilities are more likely to succumb to credit card effect behaviors than those with stronger self-regulation capacities.

Similarly, a consumer's financial sophistication acquired from experiences of credit card use is reflective of one's inclination toward credit-card-effect outcomes. Sophistication can be accrued through financial education or training (Norvilitis et al., 2006; Compton and Pfau, 2004), past experiences (Szmigin and O'Loughlin, 2010), and parental guidance (Palmer et al., 2001). These factors help consumers recognize the risks associated with the imprudent use of credit cards, which are likely to confer attitudinal and behavioral resistance to tactical targeting strategies (Compton and Pfau, 2004). Indeed, aggressive solicitation techniques that are more persuasive (sometimes arguably deceptive) than informative techniques are common in the credit card industry. This presents a challenge, particularly for inexperienced credit card users. Correspondingly, financial naivety are associated with compulsive spending, lower locus on control, lower self-efficacy and lower self-rating in money management capacities (Roberts and Jones, 2001; Lea et al., 1995; Tokunaga, 1993). Therefore, the degree of financial sophistication should determine the extent to which credit card users are equipped to avoid the ensnarling traps of credit card effect.

We conceptualize SCCMI with measures in a reflective-indicator model, where the direction of inferred causality flows from the latent construct to the measures. This is distinct from a formative model, where the direction of inferred causality flows from the measures to the construct. We follow MacKenzie et al.'s (2005) recommended criteria for distinguishing between reflective and formative measures.

First, reflective measures are used when they are manifestations of and are determined by the construct, while formative measures are used when they represent the defining characteristics that collectively explain the construct. In the present case, SCCMI manifests in behavioral and attitudinal inclinations (e.g. tendency to leave the worry of being able to afford purchases to the time the bill arrives), of which each is determined by the construct, and not vice versa. Second, reflective measurement items are used when they share a strong common theme and appear to be conceptually interchangeable since they are "sampled from the same conceptual domain" (MacKenzie et al., 2005, p. 713). On the other hand, formative measures are used if they do not share a common theme and each of them captures a unique aspect of the construct. The proposed SCCMI measures were derived from the construct's general definition and characterizations of the specific themes resulting from the qualitative interviews, which portray ways in which individuals deviate from rational credit card usage. Thus, each SCCMI measure holds an essence of the construct domain, and the measures are expected to display strong correlations with one another. Finally, all the indicators for a reflective model are expected to have the same antecedents and/or consequences, while formative indicators are not necessarily interchangeable as each 
tap unique aspects of the conceptual domain (MacKenzie et al., 2005). Measures of SCCMI are theoretically expected to share similar consequences because they all reflect the same underlying construct that portrays individual likelihood to yield to the temptations of uncontrolled credit card usage. Therefore, each SCCMI measure can be meaningfully interchangeable with another.

\section{Methodology}

Research context

Young credit card users represent a specific interest group for the present study because this cohort constitutes a lucrative target market for the credit card industry, and they are also a protected consumer group for the policy makers. In addition, young people are often described as a vulnerable consumer segment (e.g. Braunsberger et al., 2004; Szmigin and O'Loughlin, 2010) since they tend to display other unhealthy behaviors toward credit cards, such as shopping impulsiveness (Pirog and Roberts, 2007), lack of self-control (Pinto et al., 2004) and having an unrealistic overestimation of future income (Norvilitis et al., 2006; Soman and Cheema, 2002). Thus, understanding the youths' SCCMI is likely to yield important implications for marketing and public policy across nations.

Additionally, our study focusses on young credit card users in Singapore, Malaysia and the UK. Further, young consumers in these countries face varying social norms in credit card usage and regulatory intervention. Our notion of susceptibility captures the individual's internal beliefs and ideologies transgressed by external factor (Baker et al., 2005). Thus, it is conceivable that an individual's susceptibility should be analysed in the light of credit card social norms and the current regulatory restrictions since these factors are likely to effect the individuals' internal susceptibility.

Singaporean consumers' credit card spending is frugal (Gan et al., 2008) and oriented toward cost-savings and promotions (Devlin et al., 2007). Singapore applies strict credit card regulations, such as minimum income (SG\$30,000 or approximately $£ 15,000$ ) and age (minimum 21 years old) restrictions on owning a credit card (Monetary Authority of Singapore, 2004). In contrast, Malaysian consumers' credit card spending is status-oriented, as they tend to use credit cards to fund their taste for brands and products that enhance their lifestyles (Ahmed et al., 2010; Heaney et al., 2005), as well as to reflect higher social standing and financial soundness (Ramayah et al., 2002). Malaysia charges an annual service tax (RM 50 or approximately £9.50) on every credit card issued in an attempt to raise the salience of credit card spending (Bank Negara, 2011) and to curb the youths' unhealthy usage of credit cards. Meanwhile, British consumers, who face an unprecedented high availability of credit since the 1990s, are adopting a more tolerant attitude toward debt (Davies and Lea, 1995) and "a self-sustaining 'culture of indebtedness'” (Lea et al., 1993, p. 118). Moreover, regulation to control young adults' credit card usage is sparse in the UK. Students with no credit history are free to apply for student credit card (with small credit limit, usually £500) or poor-credit credit cards (with high interest rate, typically 35 percent and above). It is expected that these social and regulatory differences will reflect on the youths' different levels of susceptibility. We therefore account for these country differences in our study to construct a valid and parsimonious account of SCCMI.

\section{Item generation}

We followed Castro et al.'s (2010) recommendation for integrative mixed methods to establish a multi-item measurement scale of SCCMI. The procedure involved 
APJML

26,3

414

identifying response codes, creating thematic categories and creating thematic variables that are equivalent to measurement items. We began by conducting exploratory interviews to seek depth information on young consumers' general use of credit card as well as their perceptions, attitudes and social norms toward credit and debt. This was followed by surveys to young credit card users (18-25 years old) across the three countries. Interview participants were recruited by a convenience ("snowball") sampling procedure. We sent out e-mails to students and non-student youths identified from the student and alumni list of a university in Manchester (UK) to ask for voluntary participation in the one-to-one interview about credit card usage. We then selected the participants progressively based on a further purposeful sampling procedure to ensure that they fit with the required criteria (i.e. 18-25 years old, of Malaysian, Singaporean and UK citizenship, and own a credit card in their own names).

Qualitative methodologists contend that sampling adequacy for the interview is attained by recruiting participants who have knowledge of the research topic and when sufficient data to account for all aspects of the phenomenon have been obtained for optimal quality data and minimum dross (Morse et al., 2002). For interview-based qualitative research, recruitment of interviewees is not supposed to simulate sampling in a statistical sense, but aims at seeking typical instances of social reality from variants of the particular social setting and experiences arising from a social interaction. Such varieties in the sources of the interview data facilitate and enhance the search for depth of meaning (Crouch and McKenzie, 2006).

Guided by these principles, we recruited interview participants in a mix of three professionals and three students in Malaysia; two professionals, one unemployed, and three students in Singapore; and two professionals and four students in the UK. The interviewees owned between one to four credit cards. Through the recruitment procedure, participants were identified as belonging to either of the two main types of credit card debtors:

(1) petty debtors $(n=9)$, who use a credit card to purchase goods and services believing that they can repay before the next payment due date; and

(2) those who have developed revolving debt $(n=9)$, which are credit card balance that they cannot pay back each month (Wang et al., 2011).

Therefore, these interview samples were considered adequate on account of the participants' knowledge and experiences about credit card. These debtor varieties allowed our study to distinguish consumers who misuse credit cards and suffer the following negative consequences from those who actively avoid credit card indebtedness.

The questions that were asked during the interview included "can you describe a negative experience that you had with your credit card?" "do you think it's important to make full credit card repayments every month, and why?" and "do you control or keep track of the use of your credit card?" The data analysis identified meaningful themes consistent with the theoretical aspects underlying SCCMI. We then used the three themes to create thematic variables (measurement items). Details of the thematic categories and the resulting SCCMI initial measurement items are displayed in Table I.

The first thematic category is "unawareness of credit card effects." This theme illustrates an individual's inability to treat credit cards as cash money (i.e. falling into the cognitive traps of credit card premium, trivializing past payments and over-valuating available income). Measurement items SCCMI1-3 reflect this thematic 


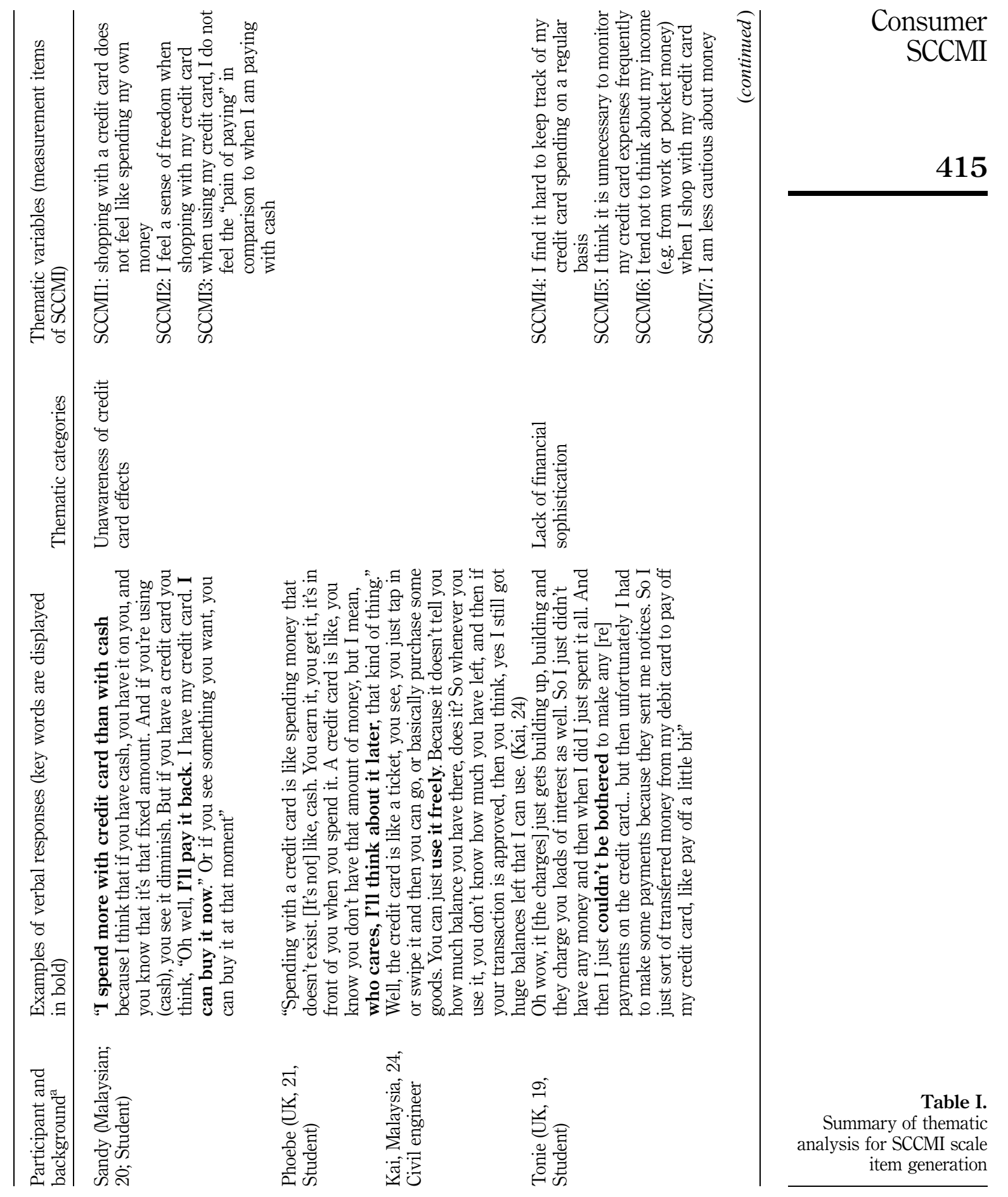


APJML

26,3

416

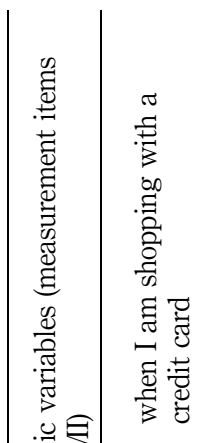

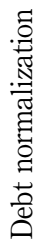

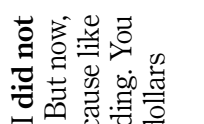

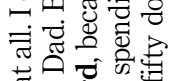

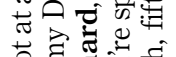

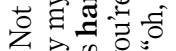

总总兽

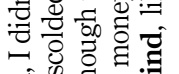

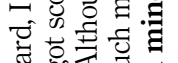

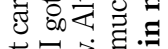

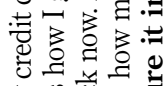

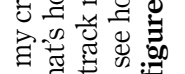

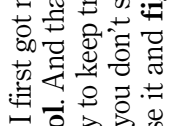

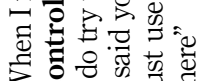

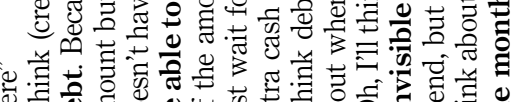

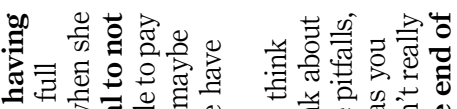

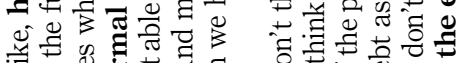

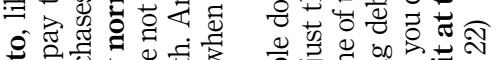

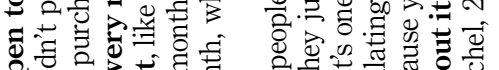

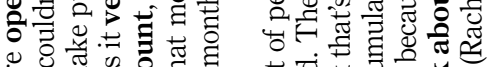

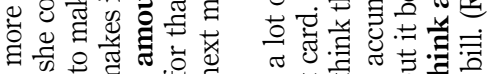

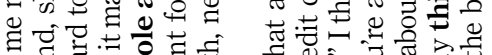

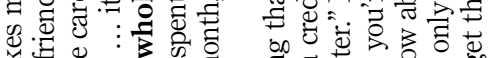

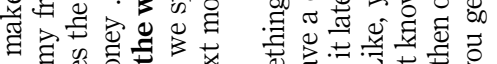

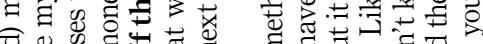

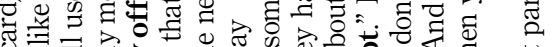

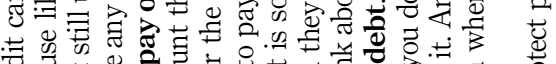

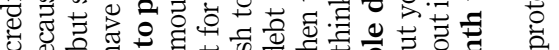

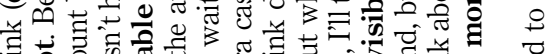

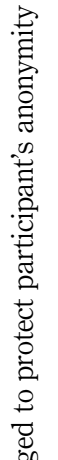

鈓

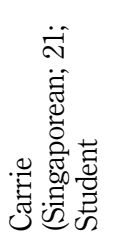

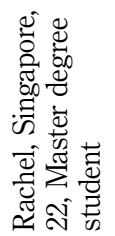

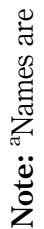


category. The second theme, (SCCMI4-7) "lack of financial sophistication" captures the degree to which individuals impose financial regulation during their credit card spending, such as budget monitoring and paying regular attention to past credit card expenses. The final theme (SCCMI8-10) reflects "debt normalization," whereby individuals rationalize their indebtedness as a common practice among their community. Similarly, Peñaloza and Barnhart (2011) argued that people tend to converge with the social pressure to normalize credit debt to maintain the "good lifestyle" choice by decompressing the feeling of guilt associated with debt.

The thematic analysis produced ten statements that were included in the initial item pool. Three senior academics with expertise in marketing and consumer behavior and four $\mathrm{PhD}$ students in Business and Management formed a review panel to evaluate the content validity of the measurement items. Subsequently, we refined the measurement items to avoid redundant, double barrel, ambiguous, and leading statements. The items used seven-point Likert-scale format ranging from one "strongly agree" to seven "strongly disagree."

\section{Scale refinement}

The resultant ten items were piloted by a questionnaire to part-time undergraduate university students enrolled in a Northwest England university's UK campus $(n=76)$ and its overseas classes that took place in Singapore $(n=105)$ and Kuala Lumpur in Malaysia $(n=46)$. These respondents were representative of young users of credit cards as they embody dual identities and experiences of working professionals and higher education students. Thus, they are less likely to be restricted to the student-specific behavior, such as need for peer approval and greater compliance to authority (Wells, 1993). The lead author attended several classes on these campuses and with the permission of the lecturers, distributed the questionnaire to the respondents (who fit the specified criterion) during their class break period. The questionnaires were returned at the end of the break period and the respondents were thanked for their cooperation. Overall, the female respondents accounted for 39, 55.2 and 38 percent in Singaporean, Malaysian and UK samples, respectively. The highest age in the sample groups was 23 years old in Singapore, 25 years old in Malaysia and 20 years old in the UK.

The pilot data was subjected to exploratory factor analysis (EFA) with principalaxis factor extraction and varimax rotation method with Kaiser normalization. An initial EFA resulted in the removal of only one reverse-worded item (item SCCMI9). Wong et al. (2003) argued that mixed-words measurement scales tend to be less effective when analyzed in a multi-country setting. Hence, this item was eliminated from the EFA and subsequent data collections. Results from a further EFA suggested a one-factor structure throughout all country samples with standardized factor loading from 0.69 to 0.89 , indicating significant and strong loadings. Cronbach's $\alpha$ values were $0.849,0.895$ and 0.863 for Singapore, Malaysia and UK, respectively, indicating strong reliability of the measurement items across the three countries.

\section{Confirmatory factor analysis (CFA)}

The final survey incorporated the remaining nine items and was conducted by convenience sampling. Official statistics show that in the UK nearly half (49 percent) of youth population aged between 18 and 24 are admitted to higher education (Department for Business Innovation and Skills, 2013), while Singapore and Malaysia reported 27 and 30 percent, respectively in the youths' university participation 
APJML 26,3

418

(Malaysian Ministry of Higher Education, 2010; Statistics Singapore, 2013). Therefore, our sampling reflected this pattern and included a mix of student and non-student young credit card users. The questionnaires were deployed to young credit card users by the lead author with an intercept technique in the vicinity of university campuses in Singapore $(n=242)$, Malaysia (Kuching and Kuala Lumpur) $(n=200)$ and UK (Manchester and London) $(n=200)$. The lead author approached students at the common areas and classes to request for their voluntary participation in return for a snack. Prior to asking the respondents to fill in the questionnaire, participants verbally confirmed their ages and type of credit cards owned to ascertain their suitability for the sampling criteria (i.e. aged 18-25, owns a credit card under his/her name, and being a Malaysia, Singapore and UK residents). The lead author delivered and collected the surveys directly in-person. The non-student participants were gathered using snowball sampling method, where the student participants passed on the link of the online versions of the survey to the persons they knew who suited the respondent criteria. The data collection period took place in summer 2011. The demographic details of the respondents are shown in Table II.

The CFA analyzed the nine-item SCCMI scale using covariance matrix and maximum likelihood estimation using LISREL 8 (Jöreskog and Sörbom, 2001). Initial CFA estimations of the measurement model resulted in a good model fit with each country's sample data confirming a unidimensional factor structure of SCCMI as specified in our conceptualization.

Additionally, we tested a three-factor model as a competing model to the proposed one-factor model. The results from the three-factor model displayed a range of good to poor model fits across samples. However, test of discriminant validity showed that the squared factor correlations in each country (which ranged from 0.48 to 0.88 ) exceeded the average variance extracted (which ranged from 0.45 to 0.60 ) due to high

\begin{tabular}{lccr}
\hline Characteristics & Malaysia & $\begin{array}{c}\text { \% of respondents } \\
\text { Singapore }\end{array}$ & UK \\
\hline & & & \\
Age & 2.5 & 2.9 & 5.9 \\
18 years & 2.9 & 3.7 & 11.8 \\
19 years & 4.9 & 12.0 & 28.1 \\
20 years & 3.9 & 14.9 & 19.7 \\
21 years & 6.4 & 17.8 & 7.4 \\
22 years & 12.3 & 25.2 & 8.9 \\
23 years & 22.1 & 14.0 & 11.3 \\
24 years & 42.6 & 9.5 & 6.9 \\
25 years & & 51.7 & 72.9 \\
Number of credit card held & 61.8 & 31.8 & 24.1 \\
1 & 22.5 & 12.4 & 1.5 \\
2 & 12.7 & 4.1 & 1.5 \\
3 & 2.9 & 84.3 & 92.6 \\
4 or more & & 15.7 & 7.4 \\
Occupation & 29.4 & & \\
Student & 70.6 & 56.6 & 45.2 \\
Non-student & & 43.0 & \\
Gender & 40.7 & & \\
Male & 59.3 & & \\
Female & & &
\end{tabular}

Table II.

Demographic profile of final survey respondents
11.8

28.1

7.4

8.9

11.3

6.9

72.9

.

1.5

2.6

55.2

44.3 
correlations between the dimensions (Fornell and Larcker, 1981). This result disconfirmed the plausibility of the three-factor rival model. Hence, the SCCMI measurement model is best represented as a unidimensional structure.

The analyses suggested elimination of four more items (item SCCMI2, SCCMI3, SCCMI7 and SCCMI10). Since factorial pattern consistency is a necessary condition for cross-country measurement invariance analysis, these four items were removed across all three samples. After this purification process, the model estimations showed excellent results of model fit across country samples. Results in Table III, indicate a convergent validity of the SCCMI measure.

We used the known-groups comparison to further establish construct validity technique (Mackenzie et al., 2011) among groups known to have high or low scores on SCCMI. This process serves as a viable alternative to nomological validity, which may provide false information as it cannot rule out spurious causes as an explanation for the findings (Mackenzie et al., 2011). The study's focus on the young people and the measure's specificity on the credit card mean that nomological network (which typically include general consumer behavior attitudes) may not provide conclusive validity of theoretical meaning of the SCCMI construct. Hence, the test of nomological validity is not appropriate in our case.

We tested for known-group-difference of SCCMI among groups of credit card users with different payer of credit card bills. Palmer et al.'s (2001) suggested that young adults whose parents assist with monthly credit card bills do not perceive the negative consequences of excessive spending and are therefore more likely to accumulate higher levels of credit card spending. Their findings also indicate that young adults who are

\begin{tabular}{|c|c|c|c|c|}
\hline Measurement items & $\begin{array}{l}\text { Singapore } \\
(n=242)\end{array}$ & $\begin{array}{l}\text { Factor loadings } \\
\text { Malaysia } \\
(n=204)\end{array}$ & $\mathrm{UK}(n=203)$ & \\
\hline $\begin{array}{l}\text { SCCMI 1: Shopping with a credit card does not } \\
\text { feel like spending my own money }\end{array}$ & $1.15(8.82)$ & $0.75(11.46)$ & $0.83(5.23)$ & \\
\hline SCCMI 4: find it hard to keep track of my credit & & & & \\
\hline $\begin{array}{l}\text { card spending on a regular basis } \\
\text { SCCMI } 5 \text {. I think it is unnecessary to monitor my }\end{array}$ & $0.85(6.38)$ & $0.64(9.37)$ & $1.14(9.56)$ & \\
\hline $\begin{array}{l}\text { SCCMI 5: I think it is unnecessary to monitor my } \\
\text { credit card expenses frequently }\end{array}$ & $1.06(9.56)$ & $0.58(8.29)$ & $1.32(11.58)$ & \\
\hline $\begin{array}{l}\text { SCCMI 6: I tend not to think about my income } \\
\text { (e.g. from work or pocket money) when } \\
\text { I shop with my credit card }\end{array}$ & & & 114 (9 41) & \\
\hline $\begin{array}{l}\text { I shop with my credit card } \\
\text { SCCMI 8: I leave the worry of paying my credit }\end{array}$ & $1.26(11.58)$ & 0.75 (11.48) & $1.14(9.41)$ & \\
\hline $\begin{array}{l}\text { card purchases to when the bill arrives } \\
\chi^{2} \text {-statistics and goodness of fit indices }\end{array}$ & $1.12(10.18)$ & $0.71(10.70)$ & $1.24(11.35)$ & \\
\hline$\chi^{2}(\mathrm{df}, p)$ & $\begin{array}{l}7.54(\mathrm{df}=5, \\
p=0.18)\end{array}$ & $\begin{array}{l}12.45(\mathrm{df}=5 \\
p=0.03)\end{array}$ & $\begin{array}{l}3.69(\mathrm{df}=5, \\
p=0.59)\end{array}$ & \\
\hline $\begin{array}{l}\text { Root mean square error of approximation } \\
\text { (RMSEA) }\end{array}$ & 0.05 & 0.08 & 0.03 & \\
\hline Non-normed fit index (NNFI) & 0.98 & 0.96 & 0.99 & \\
\hline Comparative fit index (CFI) & 0.99 & 0.98 & 1.00 & \\
\hline Standardized root mean residual (SRMR) & 0.03 & 0.04 & 0.02 & \\
\hline Composite reliability $\alpha$ & 0.91 & 0.92 & 0.82 & \\
\hline Average variance extracted (AVE) & 0.68 & 0.69 & 0.48 & $\begin{array}{l}\text { Table III. } \\
\text { Results of CFA }\end{array}$ \\
\hline Note: $t$-values are displayed in parentheses & & & & estimation of SCCMI \\
\hline
\end{tabular}


APJML 26,3

420 financially responsible for their own debts are reluctant to use their credit card recklessly. Therefore, it follows that those who pay their own credit card expenses are less SCCMI than those who are sponsored by parents, partners or other sponsors. We utilized ANOVA to compare the means from the five-items SCCMI scale between the two types of credit card bills payers in a pooled-sample analysis. The results showed a significant difference in SCCMI among those who were responsible for their own credit card bills in comparison to those who relied on parents, partners or other family members $\left(F_{(3,645)}=8.45 ; p=0.00\right)$. Therefore, the validity of the construct is confirmed through the known-group comparison analysis.

\section{Multigroup CFA}

We analyzed measurement invariance to observe SCCMI scale's equivalence across the three countries (Cheung, 2007). Without evidence of invariance, comparability across countries cannot be established and any conclusions are at best ambiguous (Steenkamp and Baumgartner, 1998). Invariance testing involves a hierarchical sequence that begins with a well-fitting multigroup baseline model for which a set of parameters is placed in an increasingly restrictive fashion (Byrne, 1998). These include configural (equivalence of factor structure and patterns of loading), metric (equivalence of factor loading values) and scalar (equivalence of intercepts) equivalences.

We computed baseline model by fixing the loading of one item to 1 and its intercept to 0 (Steenkamp and Baumgartner, 1998). Subsequently, we constrained the matrix of factor loadings to be equivalent across countries to test for full metric invariance (Steenkamp and Baumgartner, 1998). In scalar invariance, the intercepts of the regression equations were set to be equivalent across countries. The results in Table IV showed that the model fulfilled full configural and metric invariance, but only partial scalar invariance since the item SCCMI1 was non-invariant for the Malaysian sample $(\mathrm{MI}=32$, $\mathrm{EPC}=-0.70$ ). The factor loadings from the estimates in the final stage of invariance analysis are displayed in Table V. These results provide evidence for measurement invariance of the SCCMI scale for our cross-country analysis.

\section{Cross-country comparison of SCCMI}

We utilized one-way ANOVA to compare the means of SCCMI between Singapore, Malaysia and the UK. The results revealed a significant difference in SCCMI across the three countries at the 0.05 level $\left(F_{(2,646)}=6.58 ; p=0.001\right)$. Additionally, Tukey's test of multiple comparisons showed that the SCCMI level in the UK $(M=3.64, \mathrm{SD}=1.31)$ was significantly higher than in Malaysia $(M=3.27, \mathrm{SD}=1.30)$ and Singapore $(M=3.26, \mathrm{SD}=1.22)$. This suggests that on average, the UK sample exhibited greater SCCMI than both Malaysia and Singapore. These results may be attributed to the similarity of credit card ownership regulations between Singapore and Malaysia, in which both impose strict minimum income requirement of RM 24,000 p/a

\begin{tabular}{|c|c|c|c|c|c|c|c|}
\hline Tests of invariance & $\chi^{2} / \mathrm{df}$ & $\Delta \chi^{2} / \Delta \mathrm{df}$ & RMSEA & NNFI & CFI & SRMR & GFI \\
\hline Configural invariance & $25.62 / 15$ & - & 0.05 & 0.98 & 0.99 & 0.04 & 0.98 \\
\hline Full metric invariance & $40.47 / 23$ & $15.44 / 8^{\mathrm{a}}$ & 0.06 & 0.98 & 0.99 & 0.08 & 0.96 \\
\hline Full scalar invariance & $80.14 / 33$ & $55.11 / 18$ & 0.08 & 0.96 & 0.96 & 0.06 & 0.97 \\
\hline Partial scalar invariance & $48.01 / 32$ & $23.08 / 17^{\mathrm{a}}$ & 0.04 & 0.99 & 0.99 & 0.06 & 0.97 \\
\hline
\end{tabular}

Table IV.

Model comparison for multigroup SCCMI 


\begin{tabular}{|c|c|c|c|c|c|c|c|}
\hline Items & Singapore & $\begin{array}{c}\text { Factor loadings } \\
\text { Malaysia }\end{array}$ & UK & Singapore & $\begin{array}{l}\text { Intercepts } \\
\text { Malaysia }\end{array}$ & UK & $\begin{array}{r}\text { consumer } \\
\text { SCCMI }\end{array}$ \\
\hline \multirow{2}{*}{ SCCMI1 } & 1.00 & 1.00 & 1.00 & 2.03 & 3.44 & 3.44 & \\
\hline & - & - & - & (11.00) & (18.07) & (18.07) & \\
\hline \multirow[t]{2}{*}{ SCCMI4 } & 0.78 & 0.78 & 0.78 & 2.79 & 2.79 & 2.79 & \\
\hline & (12.03) & (12.03) & (12.03) & $(20.64)$ & $(20.64)$ & $(20.64)$ & 421 \\
\hline \multirow[t]{2}{*}{ SCCMI5 } & 0.88 & 0.88 & 0.88 & 1.91 & 1.91 & 1.91 & \\
\hline & (12.93) & $(12.93)$ & (12.93) & (14.37) & (14.37) & $(14.37)$ & \\
\hline \multirow[t]{2}{*}{ SCCMI6 } & 0.93 & 0.93 & 0.93 & 2.09 & 2.09 & 2.09 & \\
\hline & (13.72) & (13.72) & (13.72) & (15.72) & (15.72) & (15.72) & \\
\hline \multirow[t]{2}{*}{ SCCMI8 } & $\begin{array}{r}0.90 \\
(1228)\end{array}$ & $\begin{array}{r}0.90 \\
(1228)\end{array}$ & $\begin{array}{r}0.90 \\
(1228)\end{array}$ & 2.27 & 2.27 & 2.27 & Table V. \\
\hline & (13.28) & (13.28) & (13.28) & (17.31) & (17.31) & (17.31) & Estimation results for \\
\hline \multicolumn{7}{|c|}{ Note: $t$-values are displayed in parentheses } & multigroup SCCMI \\
\hline
\end{tabular}

(relative to the RM 42,000 average annual income) (Bank Negara, 2011) and SIN $\$ 30,000$ p/a (relative to the SIN $\$ 51,203$ average annual income) (Monetary Authority of Singapore, 2004). In contrast, the UK's liberal approach toward credit card regulation allows young and novice credit cards users to access credit cards without a minimum income requirement. Consequently, young people may be given access to credit that is greater than their actual spending capability. Soman and Cheema (2002) similarly suggested that young people tend to equate their credit limit as their future earning potential. Hence, despite the typically low credit limit (£500) authorized to students with no income, such illusive spending tendency may still result in greater susceptibility that is detrimental to young consumers' financial welfare.

\section{SCCMI and revolving credit card debt (RCCD)}

The theoretical prediction power of SCCMI is embedded in its ability to explain the variance in consumers' tendency to fall into harmful consequences of credit card misusage. The extant literature has provided theoretical and empirical evidence for the relationship between susceptibility traits and the expected behavioral outcomes to establish predictive validity of susceptibility measures. For instance, Pierce et al.'s (1996, 1998) study indicates the likelihood of young people who are susceptible to smoking to act on actual smoking. Similarly, Bearden et al.'s (1989) empirical research has supported the proposition that susceptibility to interpersonal influence is positively related to the motivation to comply with the expectations of others. In consistency with and supported by such theoretical and empirical evidence, we predict that credit card users' SCCMI is likely to yield behavioral outcomes of credit card indebtedness. In other words, those who continuously yield to the temptations of credit card spending put themselves at risk of diminished financial stability due to failure to resist or control credit card misuse and indebtedness. On account of this proposition, the theoretical prediction power of SCCMI will be evident if those higher in SCCMI have greater tendency to become RCCD.

RCCD encapsulates those who accumulate monthly credit card balances and pay interests on their outstanding credit card balances over an extended period of time. Wang et al. (2011) specified that revolving credit use is reflected by three particular outcomes and behaviors:

(1) repaying over time; 
APJML

26,3

422
(2) paying equal to or greater than minimum required payments; and

(3) using up a revolving credit limit (p.183).

Thus, we introduced five items of RCCD to evaluate the frequency in which individuals are inclined to display the above credit card behaviors. Table VI shows the results of CFA and multigroup CFA on the RCCD measure. The results suggest that the measure fulfilled partial invariance across Malaysia, Singapore and the UK.

We proceeded in estimating the hypothesized structural model involving SCCMI as the independent variable and RCCD as the dependent variable. The structural model exhibited significant $\chi^{2}$ statistics for Singapore $\left(\chi^{2}=56.13 \mathrm{df}=40, p<0.05\right)$, Malaysia $\left(\chi^{2}=98.46, \mathrm{df}=40, p<0.01\right)$ and the UK $\left(\chi^{2}=99.32, \mathrm{df}=40, p<0.01\right)$. The goodness of fit indices for Singapore (RMSEA $=0.04, \mathrm{NNFI}=0.99, \mathrm{CFI}=0.99, \mathrm{SRMR}=0.05$ ), Malaysia (RMSEA $=0.06, \quad \mathrm{NNFI}=0.97, \mathrm{CFI}=0.98, \mathrm{SRMR}=0.06$ ) and the UK $(\mathrm{RMSEA}=0.07, \mathrm{NNFI}=0.95, \mathrm{CFI}=0.97, \mathrm{SRMR}=0.07)$ satisfied $\mathrm{Hu}$ and Bentler's (1999) recommendations for a well-fitting model. Therefore, the results of the analysis indicated that SCCMI contributed significantly at the 0.01 level to explaining RCCD in Singapore $\left(\gamma=0.33, t\right.$-value $\left.=4.38, R^{2}=0.10\right)$, Malaysia $(\gamma=0.46, \quad t$-value $=5.40$, $\left.R^{2}=0.18\right)$ and the UK $\left(\gamma=0.48, t\right.$-value $\left.=5.38, R^{2}=0.18\right)$. This provides evidence for the theoretical prediction power of the SCCMI construct and usability of the measurement scale.

\section{Discussion and conclusion}

Prior studies examining the psychological effects of payment mechanisms indicate that the cues inherent in the payment methods affect current and future spending decisions (Gourville and Soman, 1998; Soman, 2001). In particular, credit card has been shown to exhibit spending cues that elicit greater spending levels, trivialization of past credit card payments and overestimation of available income. Yet, such knowledge has not been passed to the consumers' financial education, as we witness a rise in predatory credit card targeting toward youths across countries (Burton et al., 2004; Szmigin and O'Loughlin, 2010) and policy intervention that limits the young consumers' choice and rights to financial freedom (Braunsberger et al., 2004; Pechmann et al., 2011; Wood, 2010). Critiques of the current reform designed to protect young consumers advocate that policy developments should: first, not marginalize the life quality of vulnerable consumers (Pechmann et al., 2011); and second, be accompanied by additional behavioral interventions to empower vulnerable consumers to reduce their risky credit card behavior and make optimum purchase decision with their credit cards (Burton, 2008; Soman et al., 2011). The conceptualization of SCCMI makes a unique contribution to effective protection and behavioral interventions by providing the psychological attributes that entail negative consequences of credit card abuse.

SCCMI assesses the consumer's degree of sensitivity and receptivity to the temptations during credit card usage. SCCMI reflects the characteristics of: first, being unaware of the psychological effects of spending with a credit card; second, normalizing credit card debt; and third, lacking financial sophistication. Results of the CFA indicate strong validity and reliability of the SCCMI measurement scale. Discriminant validity demonstrated that the five-item unidimensional measure of SCCMI fared better than the competing three-factor model. The convergent validity of the measure was established based on the model fit statistics as well as the high values of factor loadings, $t$-values and 


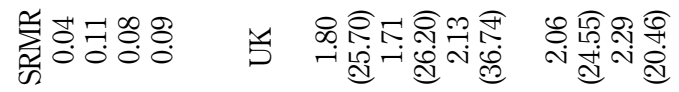

Consumer

SCCMI

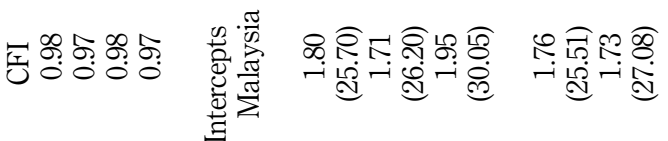

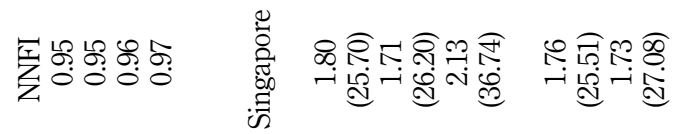

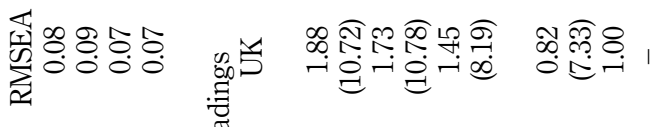

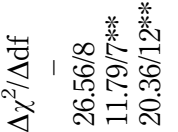

고요ำ

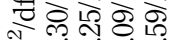

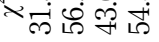

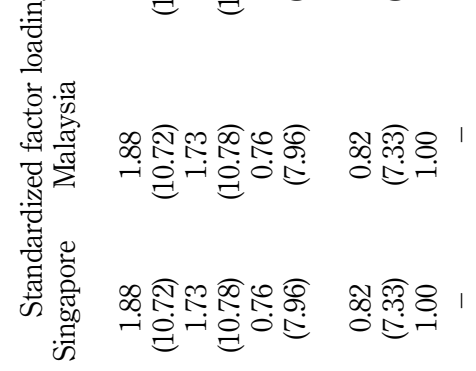

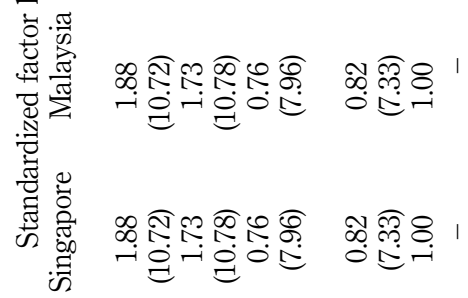

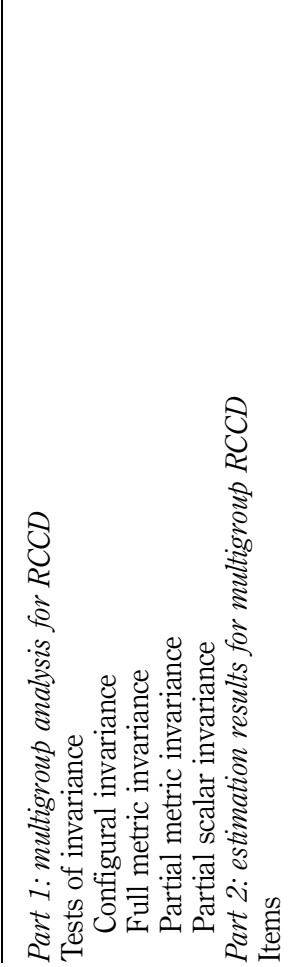

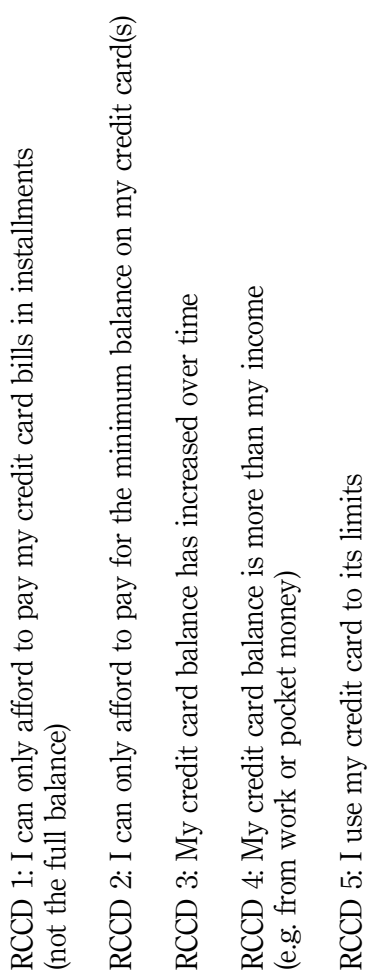

Table VI.

Multigroup analysis for revolving credit card debtors (RCCD) 
APJML 26,3 composite reliability. We established construct validity using known-group comparison, whereby SCCMI levels were higher among those responsible for their own credit card bills compared to those who relied on parents, partners or other family members.

The validity of SCCMI measure indorses its values in conception and practical usage for identifying young consumers with psychological tendencies to yield to credit card temptations. Particularly, the retained items in SCCMI measure suggest that those susceptibility manifests in attitudinal characteristics, such as disregard of credit card as real money as people do with cash, failure to monitor credit card expenses and ability to make repayments, and lack of concern over credit card debt. To reduce such susceptibility, credit card marketing in Malaysia, Singapore and the UK may focus on the monetary costs and consequences of credit card use to build the psychological link between credit card transactions with the pain associated with spending. Indeed, Burton (2008) observed that the marketing of credit card tend to display overly positive images and metaphors of credit while obscuring the negative consequences of debt, which is likely to contribute to the youths' susceptibility. Refocussing credit card marketing from lifestyle benefits to financial responsibility is likely to ameliorate young credit card users' future vulnerability and suffering from credit card misuse and indebtedness.

Similarly, public policies may seek to reduce susceptibility through behavioral intervention to avoid further restrictions on the youths' financial freedom and the credit card industry's profitability. SCCMI provides an integral diagnostic facility to identify the most susceptible credit card users, so that policy makers can design a targeted intervention to prevent credit card overuse. Government intervention programs in the countries of our study can focus on financial socialization that educates consumers about the hidden costs of using credit cards. For example, they may highlight the costs of paying with the minimum payment option or disclosing higher interest that follow after an "interest-free" period. Similarly, training programs and financial management classes can be introduced to inform and empower young consumers to use credit cards effectively. These programs can be included into the national curriculum or as an elective at lower-level education to ensure that it reaches the widest possible audiences.

Our study also hopes to reach those who feel that they might be susceptible to credit card temptations. By understanding the characteristics of the consequences of their susceptibility, young consumers should be able to improve their immunity to the credit card temptations and improve knowledge and skills to make better credit card purchase and budgeting decisions. Specifically, understanding one's SCCMI can help reduce the likelihood of experiencing future harm. As such, individuals can familiarize themselves with the essences of credit card effect, learn to improve financial sophistication and avoid accepting credit card debt (or any high-interest debt).

The cross-country investigation sheds light on the levels of SCCMI across various levels of intervention program available to protect credit card users from the potential harm of over-indebtedness. The level of the SCCMI of young consumers in the UK is significantly higher than those in Singapore and Malaysia. This difference may be explained by the fact that tighter control over credit card issuance is implemented in Singapore and Malaysia, which mandate minimum income requirements. The SCCMI scale provides a useful tool for global credit card marketers to better understand their young consumers' behavior and needs, which is key to achieve a healthy and sustainable credit card market. 


\section{Future research}

Further studies may analyses the generalizability of SCCMI scale across genders, age groups or across taxonomic factors such as education level. Since SCCMI may also be related in predictable ways to other consumer-related phenomena, it can be treated as an antecedent or moderator with some critical factors in certain behavioral issues in future research. Future research may investigate the effects of various cultural elements on SCCMI, which extends the cross-country applicability of this measure. For example, because of the Islamic prohibition of interest, future research may focus on the determinant effect of Islamic religiosity on the consumers' SCCMI. This will inform how culture- and religion-specific attitudes toward debt affect credit card ownership and usage behavior.

Theoretically, the conceptualization of SCCMI may be extended to address new issues arising from the provision of new payment methods such as electronic payments (such as PayPal) and mobile payment (such as payment stickers for smart phones). Importantly, these new payment methods seem to display similar or greater effects on consumer spending and purchase deliberation. Soman et al. (2011) argued that electronic payments are more effective than credit cards in removing a decision point for consumers to evaluate their expenses. Therefore, elements of SCCMI may be used to investigate the consumers' susceptibility to experience the negative consequences of new, technologically enhanced payment systems. Specifically, future studies may examine the consumers' characteristics of susceptibility, including: first, awareness of the liberating psychological effects of shopping with electronic and mobile payment systems; second, normalization (or denial of) their tendency to overspend with electronic and mobile payment systems; and third, financial sophistication to counter the temptations of spending freely with electronic or mobile payment systems. These elements of SCCMI can be used as a starting point for future studies that wish to explore the effects of new payment mechanisms on consumption behavior.

\section{References}

Ahmed, Z.U., Ismail, I., Sohail, M.S., Tabsh, I. and Alias, H. (2010), "Malaysian consumers' credit card usage behavior", Asia Pacific Journal of Marketing and Logistics, Vol. 22 No. 4, pp. 528-544.

Austin, M.J. and Phillips, M.R. (2001), "Educating students: an ethics responsibility of credit card companies”, Journal of Services Marketing, Vol. 15 No. 7, pp. 516-528.

Babin, B.J. and Darden, W.R. (1995), "Consumer self-regulation in a retail environment", Journal of Retailing, Vol. 71 No. 1, pp. 47-70.

Baker, S.M., Gentry, J.W. and Rittenburg, T.L. (2005), "Building understanding of the domain of consumer vulnerability”, Journal of Macromarketing, Vol. 25 No. 2, pp. 128-139.

Bank Negara (2011), "Bank Negara Malaysia press statement: responsible business practices in provision of credit cards and further enhancements to credit card infrastructure security", available at: www.bnm.gov.my/index.php?ch $=8 \& p g=14 \& a c=2226$ (accessed July 28, 2012).

BBC (2011), "Credit cards do not count as spending, say young adults", BBC News, March 2, available at: www.bbc.co.uk/news/education-12627107 (accessed October 17, 2013).

Bearden, W.O., Netemeyer, R.G. and Teel, J.E. (1989), "Measurement of consumer susceptibility to interpersonal influence”, Journal of Consumer Research, Vol. 15 No. 4, pp. 473-481.

Braunsberger, K., Lucas, L.A. and Roach, D. (2004), "The effectiveness of credit-card regulation for vulnerable consumers", Journal of Services Marketing, Vol. 18 No. 5, pp. 358-370.
Consumer

SCCMI

425 
APJML

26,3

426

Burton, D. (2008), Credit and Consumer Society, Routledge, Oxon.

Burton, D., Knights, D., Leyshon, A., Alferoff, C. and Signoretta, P. (2004), "Making a market: the UK retail financial services industry and the rise of the complex sub-prime credit market", Competition \& Change, Maney Publishing, Vol. 8 No. 1, pp. 3-25.

Castro, F.G., Kellison, J.G., Boyd, S.J. and Kopak, A. (2010), “A methodology for conducting integrative mixed methods research and data analyses", Journal of Mixed Methods Research, Vol. 4 No. 4, pp. 342-360.

Chatterjee, P. and Rose, R.L. (2012), "Do payment mechanisms change the way consumers perceive products?”, Journal of Consumer Research, Vol. 38 No. 6, pp. 1129-1139.

Cheung, G.W. (2007), "Testing equivalence in the structure, means, and variances of higher-order constructs with structural equation modeling", Organizational Research Methods, Vol. 11 No. 3, pp. 593-613.

Compton, J. and Pfau, M. (2004), "Use of inoculation to foster resistance to credit card marketing targeting college students", Journal of Applied Communication Research, Routledge, Vol. 32 No. 4, pp. 343-364.

Crouch, M. and McKenzie, H. (2006), "The logic of small samples in interview-based qualitative research", Social Science Information, Vol. 45 No. 4, pp. 483-499.

Davies, E. and Lea, S.E.G. (1995), "Student attitudes to student debt", Journal of Economic Psychology, Vol. 16 No. 4, pp. 663-679.

Department for Business Innovation and Skills (2013), "Participation rates in higher education: academic years 2006/2007 - 2011/2012", London, available at: www.gov.uk/government/ uploads/system/uploads/attachment_data/file/192188/13-p140-HEIPR_PUBLICATION_ 2011-12.pdf (accessed October 17, 2013).

Devlin, J.F., Worthington, S. and Gerrard, P. (2007), “An analysis of main and subsidiary credit card holding and spending”, International Journal of Bank Marketing, Vol. 25 No. 2, pp. 89-101.

Feinberg, R.A. (1986), "Cards as spending facilitating stimuli: a conditioning interpretation", Journal of Consumer Research, Vol. 13 No. 3, pp. 348-356.

Fornell, C. and Larcker, D.F. (1981), "Evaluating structural equation models with unobservable variables and measurement error", Journal of Marketing Research, Vol. 18 No. 1, pp. 39-50.

Gan, L.L., Maysami, R.C. and Koh, H.C. (2008), "Singapore credit cardholders: ownership, usage patterns, and perceptions", Journal of Services Marketing, Vol. 22 No. 4, pp. 267-279.

Gourville, J.T. and Soman, D. (1998), "Payment depreciation: the behavioral effects of temporally separating payments from consumption", Journal of Consumer Research, Vol. 25 No. 2, pp. 160-174.

Heaney, J.-G., Goldsmith, R.E. and Jusoh, W.J.W. (2005), "Status consumption among Malaysian consumers", Journal of International Consumer Marketing, Vol. 17 No. 4, pp. 83-98.

Henry, P., Garbarino, E. and Voola, R. (2013), "Metacognitions about consumer protection and individual responsibility in the credit card domain", Journal of Public Policy \& Marketing, Vol. 32 No. 1, pp. 32-44.

Hirschman, E.C. (1979), "Differences in consumer purchase behavior by credit card payment system”, Journal of Consumer Research, Vol. 6 No. 1, pp. 58-66.

Hu, L. and Bentler, P.M. (1999), "Cutoff criteria for fit indexes in covariance structure analysis: conventional criteria versus new alternatives", Structural Equation Modeling: A Multidisciplinary Journal, Vol. 6 No. 1, pp. 1-55.

Jöreskog, K.G. and Sörbom, D. (2001), Lisrel 8: New Statistical Features, Scientific Software International, Lincolnwood, IL. 
Kuhl, J. (1981), "Motivational and functional helplessness: the moderating effect of state versus action orientation", Journal of Personality and Social Psychology, Vol. 40 No. 1, pp. 155-170.

Kuhl, J. (1992), "A theory of self-regulation: action versus state orientation, self-discrimination, and some applications", Applied Psychology: An International Review, Vol. 41 No. 2, pp. $97-129$.

Lea, S.E.G., Webley, P. and Levine, R.M. (1993), "The economic psychology of consumer debt", Journal of Economic Psychology, Vol. 14 No. 1, pp. 85-119.

Lea, S.E.G., Webley, P. and Walker, C.M. (1995), "Psychological factors in consumer debt: money management, economic socialization, and credit use", Journal of Economic Psychology, Vol. 16 No. 4, pp. 681-701.

Loewenstein, G. and O'Donoghue, T. (2006), "We can do this the easy way or the hard way': negative emotions, self-regulation, and the law", The University of Chicago Law Review, Vol. 73 No. 1, pp. 183-206.

MacKenzie, S.B., Podsakoff, P.M. and Jarvis, C.B. (2005), "The problem of measurement model misspecification in behavioral and organizational research and some recommended solutions”, The Journal of Applied Psychology, Vol. 90 No. 4, pp. 710-730.

Mackenzie, S.B., Podsakoff, P.M. and Podsakoff, N.P. (2011), "Construct measurement and validation procedures in MIS and behavioral research: integrating new and existing techniques", MIS Quarterly, Vol. 35 No. 2, pp. 293-334.

Malaysian Ministry of Higher Education (2010), "Higher education finance and cost sharing in Malaysia”, available at: http:/gse.buffalo.edu/org/inthigheredfinance/files/Country_ Profiles/Asia/Malaysia.pdf (accessed October 17, 2013).

Mannings, R. (1999), Credit Cards on Campus: Costs and Consequences of Student Debt, Consumer Federation of America, Washington, DC.

Monetary Authority of Singapore (2004), Banking (Credit Card and Charge Card) Regulations, Monetary Authority of Singapore, Singapore.

Morse, J.M., Barret, M., Mayan, M., Olson, K. and Spiers, J. (2002), "Verification strategies for establishing reliability and validity in qualitative research", International Journal of Qualitative Methods, Vol. 1 No. 2, pp. 13-22.

Navarro-Martinez, D., Salisbury, L.C., Lemon, K.N., Stewart, N., Matthews, W.J. and Harris, A.J. (2011), "Minimum required payment and supplemental information disclosure effects on consumer debt repayment decisions", Journal of Marketing Research, American Marketing Association, Vol. 48 No. SPL, pp. S60-S77.

Norvilitis, J.M., Merwin, M.M., Osberg, T.M., Roehling, P.V., Young, P. and Kamas, M.M. (2006), "Personality factors, money attitudes, financial knowledge, and credit-card debt in college students", Journal of Applied Social Psychology, Vol. 36 No. 6, pp. 1395-1413.

Palmer, T.S., Pinto, M.B. and Parente, D.H. (2001), "College students' credit card debt and the role of parental involvement: implications for public policy", Journal of Public Policy \& Marketing, Vol. 20 No. 1, pp. 105-113.

Pechmann, C., Moore, E.S., Andreasen, A.R., Connell, P.M., Freeman, D., Gardner, M.P., Heisley, D., Lefebvre, R.C., Pirouz, D.M. and Soster, R.L. (2011), "Navigating the central tensions in research on at-risk consumers: challenges and opportunities", Journal of Public Policy \& Marketing, Vol. 30 No. 1, pp. 23-30.

Peñaloza, L. and Barnhart, M. (2011), "Living US capitalism: the normalization of credit/debt", Journal of Consumer Research, Vol. 38 No. 4, pp. 743-762.

Pierce, J.P., Choi, W.S., Gilpin, E.A., Farkas, A.J. and Merritt, R.K. (1996), "Validation of susceptibility as a predictor of which adolescents take up smoking in the United States", Health Psychology, Vol. 15 No. 5, pp. 355-361. 
APJML

26,3

428
Pierce, J.P., Choi, W.S., Gilpin, E.A., Farkas, A.J. and Berry, C.C. (1998), "Tobacco industry promotion of cigarettes and adolescent smoking", The Journal of the American Medical Association, Vol. 279 No. 7, pp. 511-515.

Pinto, M.B., Mansfield, P.M. and Parente, D.H. (2004), "Relationship of credit attitude and debt to self-esteem and locus of control in college-age consumers", Psychological Reports, Vol. 94 No. 3 Part 2, pp. 1405-1418.

Pirog, S. and Roberts, J.A. (2007), "Personality and credit card misuse among college students: the mediating role of impulsiveness", The Journal of Marketing Theory and Practice, Vol. 15 No. 1, pp. 65-77.

Prelec, D. and Loewenstein, G.F. (1998), "The red and the black: mental accounting of savings and debt”, Marketing Science, Vol. 17 No. 1, pp. 4-28.

Prelec, D. and Simester, D. (2001), "Always leave home without it: a further investigation of the credit-card effect on willingness to pay", Marketing Letters, Vol. 12 No. 1, pp. 5-12.

Raghubir, P. and Srivastava, J. (2008), "Monopoly money: the effect of payment coupling and form on spending behavior", Journal of Experimental Psychology: Applied, Vol. 14 No. 3, pp. 213-225.

Ramayah, T., Noor, N. and Lim, H.C. (2002), "Cardholders' attitude and bank credit card usage in Malaysia: an exploratory study”, Asian Academy or Management Journal, Vol. 7 No. 1, pp. 75-102.

Rick, S.I., Cryder, C.E. and Loewenstein, G.F. (2008), "Tightwads and spendthrifts”, Journal of Consumer Research, Vol. 34 No. 6, pp. 767-782.

Roberts, J.A. and Jones, E. (2001), "Money attitudes, credit card use , and compulsive buying among American college students", Journal of Consumer Affairs, Vol. 35 No. 21, pp. 213-239.

SallieMae (2009), "How undergraduate students use credit cards: Sallie Mae's national study of usage rates and trends 2009”, pp. 1-19, available at: http://static.mgnetwork.com/rtd/pdfs/ 20090830_iris.pdf (accessed October 11, 2012).

Soman, D. (2001), "Effects of payment mechanism on spending behavior: the role of rehearsal and immediacy of payments", Journal of Consumer Research, Vol. 27 No. 4, pp. 460-474.

Soman, D. (2003), "The effect of payment transparency on consumption: the effects of payment transparency on consumption: quasi-experiments from the field", Marketing Letters, Vol. 14 No. 3, pp. 173-183.

Soman, D. and Cheema, A. (2002), "The effect of credit on spending decisions: the role of credit limit and credibility", Marketing Science, Vol. 21 No. 1, pp. 32-53.

Soman, D., Cheema, A. and Chan, E.Y. (2011), "Understanding consumer psychology to avoid abuse of credit cards", in Mick, D.G., Pettigrew, S., Pechmann, C. and Ozanne, J.L. (Eds), Transformative Consumer Research for Personal and Collective Well-Being, Routledge, New York, NY, pp. 423-444.

Statistics Singapore (2013), "Educational profile of Singapore resident non-students, 2002-2012", Singapore Department of Statistics, available at: www.singstat.gov.sg/Publications/ publications_and_papers/education_and_literacy/ssnmar13-pg1-7.pdf (accessed October 17, 2013).

Steenkamp, J.E.M. and Baumgartner, H. (1998), "Assessing measurement invariance in crossnational consumer research”, Journal of Consumer Research, Vol. 25 No. 1, pp. 78-107.

Stewart, N. (2009), "The cost of anchoring on credit-card minimum repayments", Psychological Science, Vol. 20 No. 1, pp. 39-41.

Szmigin, I. and O'Loughlin, D. (2010), "Students and the consumer credit market: towards a social policy agenda”, Social Policy \& Administration, Vol. 44 No. 5, pp. 598-619. 
Tokunaga, H. (1993), "The use and abuse of consumer credit: application of psychological theory and research", Journal of Economic Psychology, Vol. 14 No. 2, pp. 285-316.

Wang, L., Lu, W. and Malhotra, N.K. (2011), "Demographics, attitude, personality and credit card features correlate with credit card debt: a view from China", Journal of Economic Psychology, Vol. 32 No. 1, pp. 179-193.

Warwick, J. and Mansfield, P.M. (2000), “Credit card consumers: college students' knowledge and attitude", Journal of Consumer Marketing, Vol. 17 No. 7, pp. 617-626.

Wells, W.D. (1993), "Discover-oriented consumer research”, Journal of Consumer Research, Vol. 19 No. 4, pp. 489-504.

Wiener, R.L., Holtje, M., Winter, R.J., Cantone, J.A., Gross, K. and Block-Lieb, S. (2007), “Consumer credit card use: the roles of creditor disclosure and anticipated emotion", Journal of Experimental Psychology: Applied, Vol. 13 No. 1, pp. 32-46.

Wong, N., Rindfleisch, A. and Burroughs, J.E. (2003), "Do reverse-worded items confound measures in cross-cultural consumer research? The case of the material values scale", Journal of Consumer Research, Vol. 30 No. 1, pp. 72-91.

Wood, K.A. (2010), "Credit card accountability, responsibility and disclosure act of 2009: protecting young consumers or impinging on their financial freedom", Brooklyn Journal of Corporate, Financial \& Commercial Law, Vol. 5 No. 2010, pp. 159-183.

Xiao, J.J., Tang, C., Serido, J. and Shim, S. (2011), “Antecedents and consequences of risky credit behavior among college students: application and extension of the theory of planned behavior", Journal of Public Policy \& Marketing, Vol. 30 No. 2, pp. 239-245.

\section{Corresponding author}

Dr Charles Chi Cui can be contacted at: charles.cui@mbs.ac.uk

To purchase reprints of this article please e-mail: reprints@emeraldinsight.com Or visit our web site for further details: www.emeraldinsight.com/reprints 